\title{
Enclaves fortificados e segregação urbana: a dinâmica contemporânea de urbanização de Ribeirão Preto'
}

\author{
Jefferson Oliveira Goulart, Camila de Oliveira Gonçalves*
}

\begin{abstract}
Resumo O artigo analisa a difusão de enclaves fortificados - espaços fechados para moradia, lazer ou consumo - na urbanização recente de Ribeirão Preto (SP), fenômeno que se intensificou nas zonas leste e sul do município por meio de condomínios residenciais horizontais e verticais, shoppings centers, conjuntos de escritórios, escolas privadas e centros de lazer. O público desses espaços manifesta no medo do crime violento o principal motivo para o abandono do espaço público. A concentração de enclaves no setor sul intensifica a segregação socioespacial entre esta região e o setor norte, território mais pobre, onde predominam conjuntos habitacionais populares e favelização.
\end{abstract}

Palavras-chave: enclaves fortificados, Ribeirão Preto, segregação urbana.

Fortified enclaves and urban segregation: the contemporary dynamics of urbanization of Ribeirão Preto

\begin{abstract}
The article analyzes the diffusion of fortified enclaves - enclosed spaces for housing, leisure or consumption - in the recent urbanization of Ribeirão Preto (SP), a phenomenon that intensified in the eastern and southern zones of the municipality through residential and horizontal condominiums, shopping malls, sets of offices, private schools and leisure centers. The public of these spaces manifests in the fear of violent crime the main reason for the abandonment of the public space. The concentration of enclaves in the southern sector intensifies socio-spatial segregation between this region and the northern sector, a poorer territory, where popular housing and slum dwellings predominate.
\end{abstract}

Keywords: fortified enclaves, Ribeirão Preto, urban segregation.

\section{Enclaves fortificados y segregación urbana: la dinámica contemporánea de urbanización de Ribeirão Preto}

Resumen El artículo analiza la difusión de enclaves fortificados - espacios cerrados para vivienda, ocio o consumo en la urbanización reciente de Ribeirão Preto (SP), fenómeno que se intensificó en las zonas este y sur del municipio por medio de condominios residenciales horizontales y verticales, centros comerciales, conjuntos de oficinas, escuelas privadas y centros de ocio. El público de esos espacios manifiesta en el temor del crimen violento el principal motivo para el abandono del espacio público. La concentración de enclaves en el sector sur intensifica la segregación socioespacial entre esta región y el sector norte, territorio más pobre, donde predominan conjuntos habitacionales populares y chabolas.

Palabras clave: enclaves fortificados; Ribeirão Preto; segregación urbana. 
Este artigo analisa a propagação de enclaves fortificados como nova tendência de configuração urbana na cidade de Ribeirão Preto no período recente (1995-2015). A pesquisa compreendeu a apreciação de estudos de caso similares e/ou comparativos em municípios do interior e a revisão da literatura sobre a evolução urbana do município e sua dinâmica de segregação socioespacial. Paralelamente, avaliou-se o novo marco regulatório da Política Urbana brasileira, sintetizada na Constituição de 1988 e na Lei Federal n 10.257/2001 (Estatuto da Cidade), além do exame da legislação urbanística municipal e de dados socioeconômicos de diferentes fontes (IBGE, Fundação Seade, Prefeitura Municipal).

Na sequência, foram catalogados os empreendimentos caracterizados como enclaves fortificados (shopping centers, condomínios residenciais fechados e escolas), procedendose à sua espacialização em mapa temático. De forma complementar, foram realizadas entrevistas com representantes do Legislativo e do mercado imobiliário, além de moradores/usuários de enclaves fortificados. Tais relatos não têm valor científico como amostra quantitativa, mas representam um recurso metodológico adicional para melhor compreender as percepções desses atores sociais.

A questão conceitual chave consistiu na hipótese de que o conceito de enclaves fortificados (CALDEIRA, 2000) é válido para explicar o mesmo fenômeno em um município do interior paulista, pois o processo de interiorização do desenvolvimento, originário da década de 1970, reproduziu nessas cidades problemas semelhantes antes privativos das grandes aglomerações urbanas: periferização, espraiamento da mancha urbana sem correspondente aporte de infraestrutura e segregação socioespacial.

A similitude analítica compreende dois aspectos principais: i) enclaves fortificados têm um conteúdo segregador porque postulam uma sociabilidade e uma ordem urbanística socialmente homogênea, contribuindo para o esvaziamento dos espaços públicos e para a erosão da cidadania mediante obstáculos ao exercício de direitos sociais e civis; ii) a tais efeitos perversos de separação e evitação sociais correspondem uma concepção "defensiva" de arquitetura e de planejamento urbano que reforça e estimula a segregação.

* Jefferson Oliveira Goulart é Cientista Político, professor da Universidade Estadual Paulista (UNESP), ORCID <http://orcid. org/0000-0001-9299-7327>. Camila de Oliveira Gonçalves é Arquiteta e Urbanista, atua como arquiteta no Estúdio Guto Requena, ORCID <http://orcid. org/0000-0002-1608-2341>.

\section{Revisitando o conceito de enclaves fortificados}

Ao longo do século XX, o processo de urbanização no Brasil foi sintetizado pela clivagem centro-periferia: diferenças urbanísticas e socioeconômicas das cidades derivaram da distinção da oferta de infraestrutura e se caracterizaram por grupos sociais que habitavam diferentes espaços - os mais ricos nas áreas centrais e os mais pobres nas periferias. Essa dinâmica obedeceu à "lógica da desordem", pela qual a maioria da população era privada de seus direitos ensejando a "espoliação urbana" (KOWARICK, 1979). Tal representação não desapareceu, mas já não é mais suficiente para explicar os processos contemporâneos de urbanização. Uma das principais razões dessa 
1 Versão ampliada deste artigo foi apresentada no XV Seminario Internacional de la Red Iberoamericana sobre Globalizazión \& Territorio (RII), Santiago de Chile, 26-28 de novembro de 2018, e resulta de pesquisa financiada pela Fundação de Amparo à Pesquisa do Estado de São Paulo (Processo Fapesp n²016/20423-1), à qual os autores agradecem pelo apoio.

2 Estudos similares sobre municípios do interior são recentes, mas valiosos inclusive para análises comparativas independente de suas diferentes abordagens teórico-metodológicas, alguns dos quais merecem registro como referência: Dal Pozzo (2015); Goulart; Bento (2011); Sposito; Goes (2013). mudança é a difusão de empreendimentos imobiliários nas franjas e periferias urbanas que atendem às populações de maior poder aquisitivo: são conjuntos de moradias horizontais ou verticais, centros de lazer e consumo, prédios de escritórios etc. Mas essa proximidade espacial está longe de representar aproximação e integração social, pelo contrário, aumenta o fosso social na medida em que esses empreendimentos são segregados, protegidos por muros, grades e cercas, marcando de forma opulenta a separação entre ricos e pobres. Tratamos, portanto, dos enclaves fortificados: "espaços privatizados, fechados e monitorados para residência, consumo, lazer ou trabalho" que atendem as classes médias-altas e altas. Por sua natureza segregadora, "ergueram-se barreiras por toda parte em volta das casas, prédios de apartamentos, parques, praças, complexos de escritórios e escolas" (CALDEIRA, 1997, p. 159).

Enclaves fortificados afirmam o distanciamento social e desigualdade entendida como um valor agregado porque o espaço público é imprevisível e perigoso por seu caráter heterogêneo. Além do conforto, da privacidade, de apelos ambientais e de outros incentivos, segurança e prestígio predominam no marketing dos negócios imobiliários desses empreendimentos. A grande aceitação desses produtos no mercado e a expansão econômica de várias regiões do interior do estado de São Paulo engendraram uma demanda potencial a fim de se reproduzir a mesma lógica em novos contextos.

A literatura tem se dedicado às grandes cidades e regiões metropolitanas, mas há uma lacuna de estudos sobre cidades do interior que exercem grande polaridade regional e que têm indiscutível importância socioeconômica. ${ }^{2}$ Ademais, esse desafio investigativo inclui testar a abrangência de um conceito pensado originalmente para as grandes cidades, como fez Caldeira (2000) de forma seminal em seu estudo sobre São Paulo e suas comparações com Los Angeles. No final da década de 1970 algumas incorporadoras passaram a construir empreendimentos imobiliários como centros comerciais, espaços para escritórios e condomínios residenciais fechados, e os mais emblemáticos são Alphaville, Aldeia da Serra e Tamboré, localizados na Região Metropolitana de São Paulo (RMSP).

O medo tem sido a justificativa mais forte para a negação do espaço público e para a adoção de barreiras físicas que criem separação, marcada por uma arquitetura defensiva que configura uma nova forma de segregação: "propriedades privadas para uso coletivo enfatizam o valor do que é privado e restrito ao mesmo tempo que desvalorizam o que é público" e, ademais, "são fisicamente demarcados e isolados por muros, grades, espaços vazios e detalhes arquitetônicos, voltados para o interior e não em direção à rua, cuja vida pública rejeitam explicitamente" (CALDEIRA, 2000, p. 258-259).

Originalmente um fenômeno restrito às grandes cidades, os enclaves fortificados se expandiram rumo ao interior paulista e se disseminaram em cidades bem servidas de redes logísticas, cujos exemplos mais notáveis são as regiões metropolitanas de Campinas, Sorocaba e São José dos Campos, servidas pelas melhores rodovias do país. Na sequência, se espalharam por várias regiões do estado de São Paulo, sobretudo naquelas em que existiam dois ingredientes fundamentais: um vigoroso mercado imobiliário e um público consumidor para seus produtos, intensificando a fragmentação socioespacial. 
Figura 1: Mapa de localização de Ribeirão Preto. Fonte: Prefeitura Municipal de Ribeirão Preto.
4 Cartogramas produzidos por Hervé Théry para a Fundação Seade (2005) mostram que há um "V central" e uma "dorsal paulista" onde se encontram, atualmente, o maior eixo de circulação e de densidade econômica do estado (SPOSITO; GOÉS, 2013). O município de Ribeirão Preto está inserido nessa geografia.

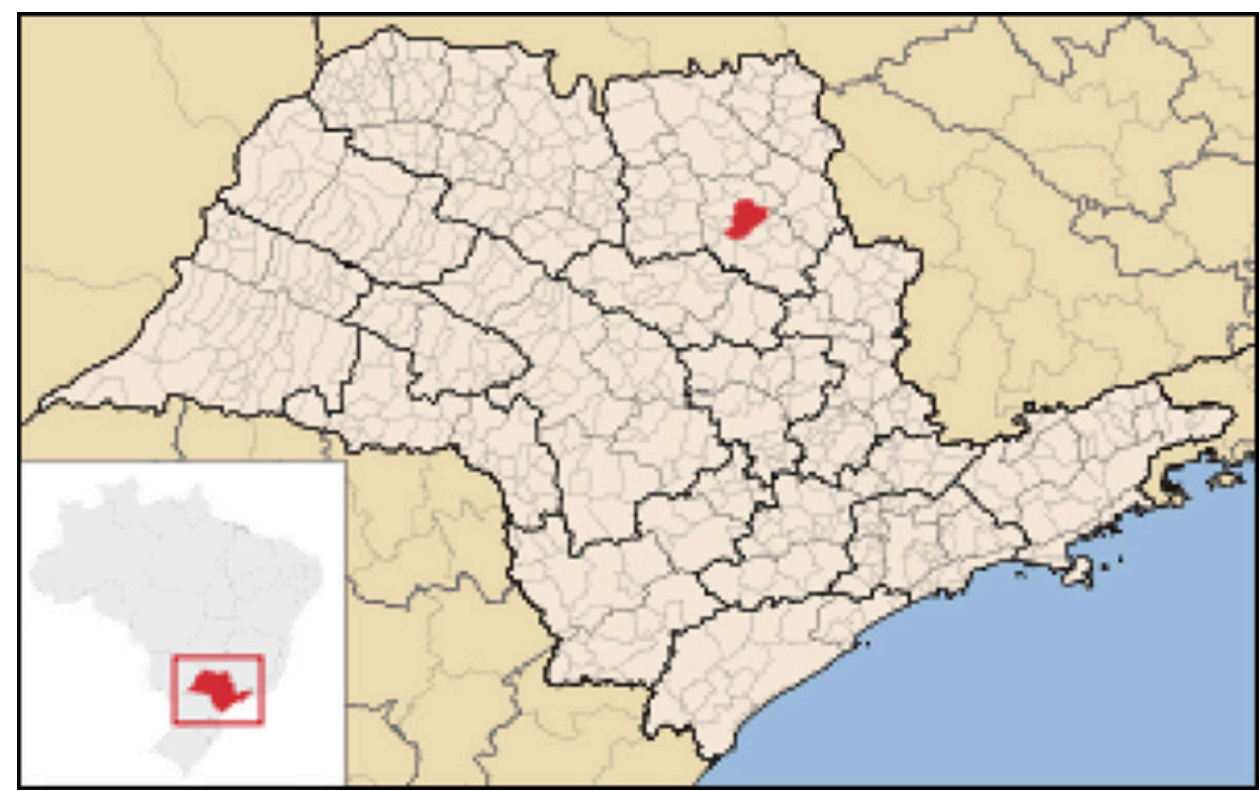

\section{Ribeirão Preto: o objeto de estudo}

Ribeirão Preto se situa no interior noroeste do estado de São Paulo, a 315 km da capital (Figura 1). De acordo com o IBGE/Censo 2010, tem população de 654.893 habitantes, com Taxa Geométrica de Crescimento de 1,36\% (superior à taxa do estado, de 0,85\%). Com território de $650.916 \mathrm{~km}^{2}$, seu grau de urbanização é de $99,72 \%$ e ocupa a $22^{a}$ posição $(0,8)$ no ranking do Índice de Desenvolvimento Humano estadual (IDH). Sua região de influência abriga 71 municípios, classificada como uma Capital Regional B³ , com uma posição viária privilegiada pela conexão com a rodovia Anhanguera, importante eixo viário que liga a capital paulista a Campinas, ao Triângulo Mineiro e a Brasília. Ademais, possui um PIB per capita de $R \$ 43.969,27$, valor ligeiramente superior à média estadual $(\mathrm{R} \$ 43.544,61)$.

As políticas de descentralização industrial da RMSP - entre os anos de 1970 e 1985, no bojo do II Plano Nacional de Desenvolvimento (PND) - proporcionaram intensa modernização agrícola e o desenvolvimento do interior paulista (NEGRI, 1988). A criação do Programa Nacional do Álcool, em 1975, e a ampliação da rodovia Anhanguera impulsionaram a dinamização econômica da região, aumentando a demanda por mão-de-obra não qualificada para trabalhar na lavoura canavieira, gerando aumento de migrações de outros estados (FERNANDES et al., 2004). A população urbana de Ribeirão Preto triplicou entre os anos de 1970 e 2010, passando de 196.242 habitantes para 603.401 habitantes (Tabela 1).

O desenvolvimento técnico-científico-informacional, que consiste na remodelação do espaço pela inovação da técnica, da ciência e da informação (SANTOS, 1993), difundiu uma modernização antes concentrada. Esse processo, todavia, não se deu de forma igualitária pelo território paulista. ${ }^{4}$ Algumas áreas foram afetadas devido à influência da agropecuária e da agroindústria, casos das regiões de Campinas e de Ribeirão Preto (NEGRI, 1988). 


\begin{tabular}{|c|c|c|c|c|c|c|c|}
\hline Ano & 1950 & 1960 & 1970 & 1980 & 1991 & 2000 & 2010 \\
\hline População urbana & 63.312 & 119.49 & 196.242 & 300.828 & 416.704 & 502.760 & 603.401 \\
\hline População Total & 92.160 & 147.361 & 218.584 & 318.496 & 431.131 & 504.923 & 604.682 \\
\hline
\end{tabular}

Tabela 1: Município de Ribeirão Preto - Evolução Demográfica 1940/2010. Fonte: elaborado pelo autor, com dados dos Censos Demográficos do IBGE.

\footnotetext{
5 Para a relação completa das áreas dos conjuntos habitacionais, consultar o sítio da COHAB-RP. Disponível em: <http://www. ribeiraopreto.sp.gov.br/cohab/ i08extensao.php>.
}

É nesse contexto de modernização e industrialização do último quarto do século XX que se observa de maneira mais intensa a segmentação socioespacial e a deterioração das condições de vida urbana das populações mais pobres: o espraiamento da cidade envolveu a "correlação expressa pelo trinômio que compreende a difusão de inovações tecnológicas no setor sucroalcooleiro, o perfil das migrações no estado de São Paulo e a segregação urbana" (FERNANDES et al., 2004, p. 55). Ribeirão Preto se consolidou como núcleo de aglomeração urbana na década de 1980 e os anos de 1990 marcam o aprofundamento da crise urbana com a adoção de políticas neoliberais (DAL POZZO, 2015; FIGUEIRA, 2013). Assim, a cidade vivenciou favelização e aumento de suas periferias nas zonas norte e oeste da cidade, ao mesmo tempo em que ocorreu intenso crescimento das áreas mais ricas, em especial na zona sul, notadamente por meio de enclaves fortificados (condomínios residenciais fechados, shopping centers, edifícios para o setor terciário).

A Companhia Habitacional de Ribeirão Preto (COHAB-RP) exerceu papel determinante na expansão urbana, selando a apartação socioterritorial dos bairros periféricos a oeste e, principalmente, ao norte. Paradoxalmente, a produção mais intensa da COHAB-RP ocorreu na "década perdida" (1980), com a construção de 16.207 unidades e do seu maior empreendimento habitacional, o Jardim Quintino Facci ll. Este conjunto conta com 3.112 unidades e está localizado no extremo norte da cidade, nos últimos subsetores localizados ainda dentro do Anel Viário (N8 e N10), totalizando 1.199.296,44 m² de área. ${ }^{5}$ Os conjuntos implantados nesse período se localizam distantes do centro, caracterizados pela falta de transporte público, ruas sem pavimentação, iluminação pública e saneamento básico (FERNANDES et al., 2004). Assim se afirmou na cidade a lógica centro-periferia que caracterizou a urbanização do país na segunda metade do século XX. Em 41 anos, a COHAB-RP construiu 36.741 unidades habitacionais, a maioria nos setores norte e oeste (Figura 2): em média, 896.12 unidades/ano.

Recentemente, o Programa Minha Casa Minha Vida (PMCMV) passou a protagonizar a provisão de habitação social: dos 12 conjuntos implantados pela COHAB-RP até 2016, 10 foram produzidos pelo PMCMV, somando 2.584 unidades.

Em 2017 iniciaram-se as obras do maior conjunto habitacional da COHAB-RP: o empreendimento Vida Nova Ribeirão irá disponibilizar 6.991 casas térreas no setor norte, em área que extrapola o perímetro urbano. Diferente das décadas de 197080, este empreendimento é vendido como "bairro planejado" com infraestrutura básica completa, além de equipamentos públicos institucionais e de lazer. Ainda que tenha concentrado sua produção em áreas adensadas já urbanizadas dentro do Anel Viário, o PMCMV reforçou a segregação socioespacial da cidade: não há nenhuma 
Figura 2: Município de Ribeirão Preto - Conjuntos habitacionais implantados pela COHAB-RP Fonte: elaborado pelo autor, com dados extraídos de Dal Pozzo (2015); da ferramenta Google Earth; do site da revista Revide, disponível em <https://www. revide.com.br/noticias/cidades/ residencial-da-cohab-ainda-nao-encontrou-compradores/>. Acesso: 22 out. 2017; do portal de notícias de Ribeirão Preto, disponível em <ribeirao-preto.org/2014/10/ ribeirao-preto-ganhara-mais-736-apartamentos-do-mcmv.html>. Acesso: 22 out. 2017.

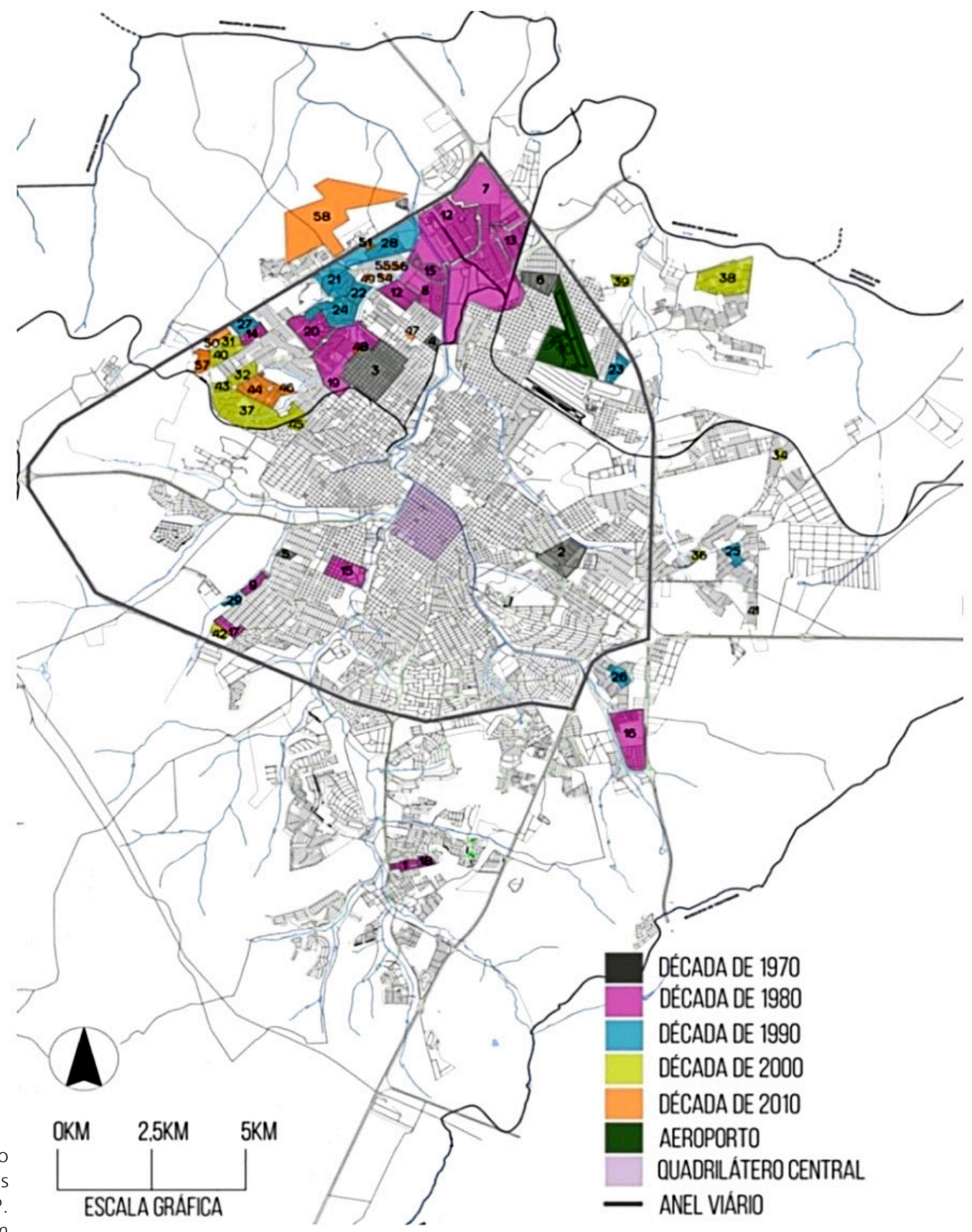


unidade habitacional construída nos setores leste e sul, apenas nos setores norte e oeste e mais especificamente a noroeste. É também nos setores norte e oeste que se concentram as favelas, onde hoje existem 70 áreas ocupadas de forma irregular por moradores sem-teto.

Levantamento do Plano de Habitação de Interesse Social (PLHIS) indicou, em 2010, 26.077 pessoas em assentamentos precários (3,98 \% da população), evidenciando a dicotomia da espacialização socioeconômica entre o norte periférico pobre e centrosul rico.

No plano econômico, há crescimento do setor terciário através do valor adicionado no PIB do município. O setor terciário é o maior gerador de empregos na cidade, seguindo a tendência estadual. De acordo com os dados de capital humano organizados pela Federação das Indústrias do Estado de São Paulo (FIESP), de 226.584 pessoas empregadas em 2015, 127.468 (56\%) estavam no setor de "Serviços e Administração Pública" e 61.566 (27\%) no comércio.

\section{Os parâmetros institucionais}

O Plano Diretor do município foi instituído pela Lei Complementar n 501/1995 e revisado pela Lei Complementar $n^{\circ}$ 1.573/2003, com instrumentos de regulação urbana (Art. $5^{\circ}$ ) originários do Estatuto da Cidade. Contudo, na contramão de uma cidade democrática e igualitária, e lei original instituiu o setor sul como vetor de crescimento da área urbanizada (Art. $8^{\circ}$ ), fomentando investimentos públicos e privados em área da cidade que já havia iniciado um intenso processo de valorização e especulação imobiliária com a inauguração do primeiro shopping da cidade, o Ribeirão Shopping, em 1981.

A revisão do Plano Diretor de 2003 trouxe poucas modificações, servindo como adequação ao Estatuto da Cidade, incluindo outros dispositivos: IPTU Progressivo, Operação Urbana

6 Entrevista com o vereador Marcos Papa (Partido Rede Sustentabilidade) e com a sua assessora, Andrea Campaz Bombonato, permite compreender o quadro de forças imobiliárias: houve intenso lobby imobiliário por parte do Sindicato da Indústria da Construção Civil do Estado de São Paulo (SindusCon-SP) e de empreiteiras (não nomeadas) para que se diminuíssem as restrições de ocupação do setor leste, questionando os estudos de fragilidade ambiental desse setor. Informações disponíveis em: <g1.globo.com/sp/ribeirao-preto-franca/noticia/2014/02/ camara-rejeita-novo-plano-diretor-de-ribeirao-e-vereador-fala-em-acordo.html>; e em <acidadeon.com/ribeiraopreto/ cotidiano/NOT,2,2,1241404,Gov erno+nao+convence+Camara+a +excluir+aquifero+do+Plano+Dir etor.aspx>. Acesso: 07 jun. 2017 Consorciada, Estudo de Impacto de Vizinhança (EIV). Ainda Foram acrescentados os

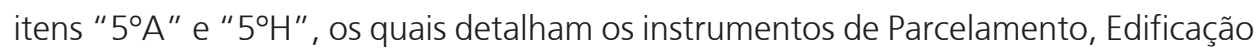
ou Utilização Compulsória, IPTU Progressivo, Direito de Preempção, Transferência do Direito de Construir, Outorga Onerosa do Direito de Construir e Operações Urbanas Consorciadas. De todos esses instrumentos, o único utilizado pelo município é o EIV, que, uma vez auto-aplicativo, não precisa de regulamentação por lei específica.

Foi tentada nova revisão do PD em 2014, mas rejeitada na Câmara dos Vereadores. O ponto de maior discordância referiu-se à inclusão de uma emenda, por parte de onze parlamentares, que solicitava a supressão do artigo 23, que proíbe a urbanização na bacia do Córrego das Palmeiras II, considerada importante ponto de recarga do Aquífero Guarani (o maior manancial de água doce subterrâneo do mundo). A revogação deste dispositivo permitiria a exploração imobiliária no setor leste da cidade, região de grande interesse imobiliário por já conter $14,4 \%$ dos enclaves residenciais horizontais da cidade - a segunda maior porcentagem depois do setor sul $(79,4 \%)(\mathrm{PECCl}, 2014)$. Em 2017, o prefeito Duarte Nogueira (PSDB) tentou igualmente suprimir o artigo 23, e novamente esse apelo foi rejeitado. ${ }^{6}$

Em 17/10/2017 foi protocolado o Projeto de Lei Complementar n 68/2017 com um novo texto de revisão do Plano Diretor de Ribeirão Preto, que contém alterações em 
7 Para a relação completa de loteamentos fechados que conseguiram a aprovação do fechamento, os que ainda estão com seus processos em andamento e outros que ainda não a adquiriram, ver Pecci (2014, p. 34-37). dois temas cruciais: a urbanização da área de recarga do Aquífero Guarani, mediante restrições ambientais a serem detalhadas na revisão da Lei de Parcelamento, Uso e Ocupação do Solo, além da exclusão do setor sul como vetor de crescimento da cidade, com a supressão do artigo $8^{\circ}$ do PD.

A legislação urbanística que mais explicita as desigualdades socioespaciais, incidindo diretamente na produção do espaço urbano, é a Lei de Parcelamento, Uso e Ocupação do Solo (Lei Complementar n 2157/2007). Devido à declaração de inconstitucionalidade de sua revisão feita pela Lei Complementar $n^{\circ}$ 2505/2012, esta tentou tornar legal a situação dos loteamentos fechados da cidade. Decisão do Tribunal de Justiça do Estado de São Paulo, porém, declarou a lei inconstitucional através de uma Ação Direta de Inconstitucionalidade. A Lei Complementar $n^{\circ} 2.505 / 2012$ foi suspensa pelo Decreto Legislativo $n^{\circ}$ 75/2015, de 27/02/2015.

A normatização dos loteamentos fechados é polêmica, pois o parcelamento do solo que os originou foi regido pela Lei Federal $n^{\circ}$ 6.766/1979. Portanto, o fechamento de um loteamento originado do parcelamento implica transformar áreas públicas em áreas para uso privado de seus moradores. A norma que regulamenta os condomínios é a Lei Federal n 4.591/1964, e é nesta que a Lei de Parcelamento, Uso e Ocupação do Solo de Ribeirão Preto fundamenta juridicamente a figura do condomínio urbanístico, até então inédita na legislação do município.

Houve duas tentativas de se tentar legalizar esses loteamentos fechados. Em 2004, foi criada a Lei Complementar $n^{\circ} 1.762$, que autorizava o encerramento de ruas de loteamentos, o que tornaria legal o fechamento destes. Mas esta lei também foi considerada inconstitucional pelo Tribunal de Justiça do Estado de São Paulo em 2008. A Prefeitura ficou proibida de autorizar empreendimentos desse tipo de figura urbanística. A segunda tentativa foi a Lei Complementar n².462/2011, por meio da qual se estipulou um prazo de dois anos para que as associações de moradores desses loteamentos protocolassem o pedido de fechamento. Segundo Pecci (2014), quando o prazo se encerrou, em 13/07/2013, havia apenas 19 processos protocolados com pedidos de regularização de loteamentos fechados e, destes, apenas 3 loteamentos conseguiram decreto de aprovação. ${ }^{7}$ Portanto, tanto os loteamentos fechados em processo de análise quanto os demais são juridicamente ilegais. O esforço para tentar regularizar e legalizar a figura urbanística do loteamento fechado, além da não fiscalização e da não punição dos moradores desses loteamentos, se explica pelo fato de que, dos 57 loteamentos fechados existentes na cidade, 55 deles se localizam no setor sul (o principal vetor de expansão urbana local), onde se concentra a população de maior poder aquisitivo.

O macrozoneamento e a definição de áreas especiais na cidade conferem ao setor sul as melhores condições de atração do mercado imobiliário, por possuir grandes vazios urbanos com malha urbana pouco consolidada e estar situado fora do anel viário e, portanto, além da Zona de Urbanização Preferencial (ZUP). Estes subsetores fazem parte da Zona de Urbanização Controlada (ZUC), que permite maiores dimensões mínimas para loteamentos.

Em síntese, a legislação urbanística possui um caráter contraditório: ao mesmo tempo em que absorveu eixos progressistas do marco institucional (Constituição Federal e 
8 Disponível em: <http:// ri.multiplan.com.br/ptb/1564/ ExpVIIIRBSPort.pdf>. Acesso: 07 jun. 2017.
Estatuto da Cidade), não foram regulamentados os instrumentos que garantiriam esses preceitos, além da permissividade na oferta de condomínios fechados e uma explícita preferência por desenvolver os setores leste e, principalmente, o sul.

\section{Enclaves fortificados e segregação socioespacial}

Com base na acepção de Caldeira (2000), os enclaves fortificados locais foram catalogados, mapeados e listados em formato espacial. Além disso, foram organizados de maneira cronológica ao longo do recorte temporal (1995-2015).

A cidade tem quatro shoppings. O Ribeirão Shopping foi o primeiro, inaugurado em 1981, passou por oito expansões, tornando-se o maior centro de compras do Brasil em Área Bruta Locável (ABL) do portfólio da Multiplan, com 69,4 mil m $\square$ de ABL e 91,3 mil $\mathrm{m}^{2}$ de Área Bruta Comercial. ${ }^{8}$ As expansões não se limitaram ao aumento da área construída, pois, entre os anos de 2002 e 2013, criaram também um complexo comercial em seu entorno: em 2002 foi inaugurado o Hotel Íbis; em 2005 o edifício comercial Ribeirão Office Tower; e, em 2012, uma torre de escritórios para venda, o Centro Profissional Ribeirão Shopping.

Em 2013, a rede Multiplan inaugurou o Shopping Iguatemi, um complexo imobiliário que, em parceria com a Vila do Ipê Empreendimentos, construiu um shopping com $43.648 \mathrm{~m}^{2}$ de Área Bruta Locável (ABL) e anunciou a construção de oito torres comerciais, nove edifícios corporativos, 18 torres residenciais, hotel, sete condomínios horizontais, escola, centro de eventos e campo de golfe. Segundo Pecci (2014), o Shopping Iguatemi funciona como um "grande centro catalisador" de uma área que já funciona como "um grande polo de especulação imobiliária".

O Shopping Santa Úrsula, único localizado no centro, foi incorporado à empresa Multiplan em 2010, que promoveu reformas para que se adequasse aos padrões da empresa. A Multiplan exerce, portanto, quase um monopólio desse tipo de complexo comercial na cidade. Por último, o Novo Shopping se localiza na região sudeste. Seu público alvo é a classe média e sua área é constantemente ampliada para abrigar novas lojas e serviços, por exemplo, a inauguração, em 2002, do Espaço Empresarial, capaz de sediar eventos e acomodar escritórios corporativos e de serviços, além da inauguração do Poupatempo em 2003 e de contar com um hotel contíguo.

Instalados próximos ao anel viário, os shoppings e seus complexos indicam a atratividade do setor terciário de Ribeirão Preto sobre as cidades menores da região, pois criam novas centralidades, atraindo consumidores e o mercado imobiliário.

Dos 162 enclaves residenciais da cidade, 130 se concentram nos subsetores sul e, destes, 113 se encontram fora do Anel Viário. Assim, "um terço de toda área urbanizada do setor está fechada, o que demonstra a priorização dos condomínios nesta região" (PECCl, 2014, p. 66).

No setor leste se encontra a segunda maior quantidade de enclaves residenciais fechados (23), 17 dos quais localizados fora do anel viário. Dois destes, em antigas chácaras de recreio, são os maiores, com áreas superiores a 1 milhão de $\mathrm{m}^{2}$. Os setores oeste e norte possuem as menores quantidades desse tipo de enclave. A presença desse tipo 
de empreendimento no setor norte sugere a hipótese de que esses enclaves estão começando a ser consumidos também para classes mais baixas, mesmo em menor escala.

Já o levantamento das instituições privadas de ensino compreendeu escolas de educação infantil, faculdades e universidades, consideradas enclaves fortificados porque aderem à estética da arquitetura defensiva e porque são seletivas, pagas, reforçando seu caráter socialmente homogêneo. Mesmo que o maior número dessas instituições esteja localizado no setor sul (41), há no setor leste outras 32 unidades, seguidas por 31 no setor norte, 22 no setor oeste e 19 no setor central. Ainda que o setor central tenha grande poder atrativo, a orientação do desenvolvimento urbano e econômico está focada na região sul, exercendo grande influência nas regiões sudoeste e sudeste, onde se concentram os habitantes de maior poder aquisitivo, agravando a dicotomia na cidade entre norte (pobre) e sul (rico). A Figura 3 sintetiza a espacialização dos diferentes tipos de enclaves.

O tratamento das distintas expressões de incivilidade na trajetória do homem público indica que "civilidade é tratar os outros como se fossem estranhos que forjam um laço social sobre essa distância social" (SENNETT, 1993, p. 323). E há uma modalidade de incivilidade que se mostra como "perversão da fraternidade na experiência comunal moderna", isto é, a tendência contemporânea de forjar traços de personalidade e comportamentos sociais mais exclusivos faz com que "quanto mais estreito for o escopo de uma comunidade formada pela personalidade coletiva, mais destrutiva se tornará a experiência do sentimento fraterno. Forasteiros, desconhecidos, dessemelhantes, tornaram-se criaturas a serem evitadas" (Idem, p. 325). Tal concepção permanece atual e ajuda a explicar as percepções dos cidadãos sobre si (os iguais) e os outros (os "dessemelhantes").

De modo geral, a segurança foi ratificada como a principal razão dos entrevistados optarem por enclaves fortificados residenciais. Dentre outras motivações, a segunda mais citada foi a realização de um bom negócio imobiliário ao comprar um imóvel que atendesse às necessidades de segurança, lazer e localização com um preço considerado adequado. Outros entrevistados ainda citaram a proximidade com o trabalho.

Resposta unânime foi a percepção de que a violência urbana cresceu, aumentando a sensação de insegurança das pessoas. Para problematizar, foi feito um levantamento das estatísticas criminais de Ribeirão Preto e de outras três cidades do interior paulista para efeito de comparação e contextualização: Campinas, Sorocaba e Santos. Os números do estado de São Paulo também foram adicionados na Tabela 2 para que se possa analisar a relevância de cada tipo de crime nas cidades escolhidas.

Os dados permitem inferir que: a) o homicídio doloso é o crime com as menores ocorrências em todas as cidades, além de todas apresentarem uma queda significativa de sua frequência; b) a ocorrência dos crimes listados em Ribeirão Preto é inferior ao registrado em Campinas e muito menor no caso de furto e roubo de veículos, fato parcialmente explicado pela diferença demográfica; c) a frequência de homicídio doloso em Ribeirão Preto foi menor que a de Sorocaba, porém, maior que a de Santos em três anos; d) Ribeirão Preto, Campinas e Santos apresentaram aumento na ocorrência de furtos, conforme tendência estadual, sendo os números de Ribeirão Preto maiores 
Figura 3: Município de Ribeirão Preto - Mapa com a localização Geral de Enclaves Fortificados. Fonte: elaborado pelo autor, com base em dados extraídos de: Pecci (2014); Dal Pozzo (2015); Diretoria de Ensino - Região de Ribeirão Preto (2017); site do Sindicato de hotéis, restaurantes, bares e similares de Ribeirão Preto e região (2017).

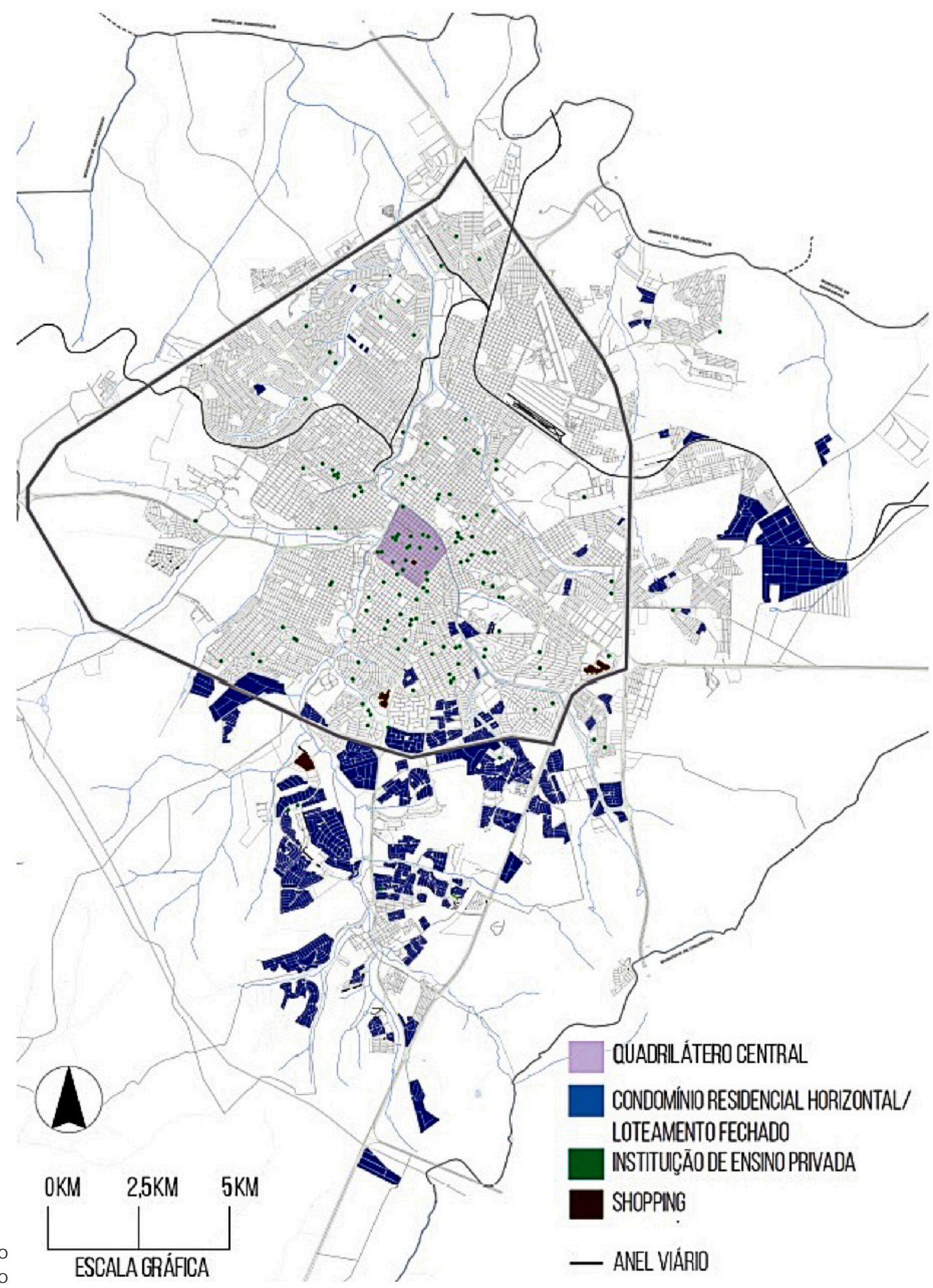


9 Em agosto de 2016 a presidente Dilma Rousseff foi afastada definitivamente de seu cargo após um longo e controvertido processo de impeachment. Este processo gerou intensa polarização ideológica no país, além de ter contribuído para a sua desestabilização político-institucional e econômica em meio a uma recessão que se agravou a partir de 2015. Para uma interpretação original desses episódios, particularmente do ponto de vista da ação das elites, ver Souza (2016).

Tabela 2: Crimes praticados nos municípios de Ribeirão Preto, Campinas, Sorocaba e Santos/2001-2015. Fonte: elaborado pelo autor, com dados da Fundação Seade e da Secretaria de Segurança Pública de São Paulo. que os de Santos e Sorocaba; e) o número de roubos aumentou em Ribeirão Preto, Sorocaba e Santos, tendo esta última fechado 2015 com o número mais alto em comparação com as demais; f) as ocorrências de furto e roubo de veículo aumentaram em Ribeirão Preto e Sorocaba; g) em Ribeirão Preto houve uma queda importante de crimes violentos, porém, com aumento de crimes que não envolvem violência física, como furtos e roubos de veículos.

Os índices de criminalidade de Ribeirão Preto não diferem radicalmente dos índices de cidades de porte similar, de forma que as estatísticas da criminalidade não seriam suficientes para justificar a produção exacerbada de enclaves residenciais, considerando ainda que um terço da área urbanizada de seu setor sul já está fechada (PECCI, 2014, p. 66).

As classes média-alta e alta residentes de enclaves estabelecem relações "ambíguas de dependência e evitação, intimidade e desconfiança" (CALDEIRA, 2000, p. 272), para com seus empregados, ainda que, na escala da cidade, tenham se libertado da mistura de classes. Uma das características principais desses "novos habitatsfechados" são "mecanismos pautados na discriminação que ferem os princípios básicos da Constituição Brasileira" (SPOSITO e GÓES, 2013, p. 241). Tal discriminação aparece nas explicações dos entrevistados sobre o aumento da violência urbana: as respostas a essa pergunta foram genéricas e simplistas, e a maioria identificou na desigualdade social e na atual crise econômica e política do Brasil ${ }^{9}$ as causas para o aumento da violência, de forma que o aumento do desemprego e da falta de oportunidade tenha transformado essas mesmas pessoas nos agentes da violência.

Ao identificar pessoas de classes sociais mais baixas como responsáveis pela violência urbana cria-se uma generalização estereotipada dessa população. Tal distinção serve para justificar medidas discriminatórias e o próprio auto-isolamento, vendo no "dessemelhante" uma pessoa a ser evitada.

\begin{tabular}{c|c|c|c|c|c|c|c|c|c|c|c|c|} 
Cidade & \multicolumn{3}{|c|}{ Ribeirão Preto } & \multicolumn{3}{c|}{ Campinas } & \multicolumn{3}{c|}{ Sorocaba } & \multicolumn{3}{c|}{ Santos } \\
\hline Habitantes & \multicolumn{3}{|c|}{654.893} & \multicolumn{3}{c|}{1.150 .753} & \multicolumn{3}{c|}{637.436} & \multicolumn{3}{c}{425.621} \\
\hline Crimes & 2001 & 2008 & 2015 & 2001 & 2008 & 2015 & 2001 & 2008 & 2015 & 2001 & 2008 & 2015 \\
\hline $\begin{array}{c}\text { Homicídio } \\
\text { Doloso }\end{array}$ & 176 & 36 & 46 & 542 & 141 & 121 & 120 & 69 & 53 & 103 & 16 & 11 \\
\hline Furto & 9.957 & 10.198 & 10.740 & 13.608 & 14.922 & 18.101 & 7.672 & 6.344 & 7.160 & 5.585 & 6.483 & 6.454 \\
\hline Roubo & 3.428 & 2.861 & 3.500 & 10.873 & 8.948 & 8.887 & 2.004 & 1.292 & 2.980 & 2.986 & 3.187 & 4.317 \\
\hline $\begin{array}{c}\text { Furto e } \\
\text { Roubo de } \\
\text { Veículo }\end{array}$ & 1.225 & 1.850 & 2.833 & 14.118 & 7.528 & 6.817 & 1.563 & 1.387 & 3.543 & 1.819 & 2.282 & 1.689 \\
\hline
\end{tabular}


Figura 4: Anúncio do residencial fechado Fazenda Santa Maria. Fonte: Revista REVIDE, p. 2-3, ed. 43, 2010.
As vantagens de se morar em um enclave residencial, mencionadas por seus residentes, são refletidas em anúncios que vendem esse produto. Além da ênfase na segurança, moradores mencionaram também o silêncio e a tranquilidade do condomínio, de forma que "nem parecia que estavam na cidade". Desejos estes explorados pelo marketing desses empreendimentos (Figura 4). A ênfase na localização demonstra a necessidade de se garantir o status associado aos empreendimentos. Também são enfatizados os aspectos ambientais devido à proximidade com áreas verdes, pois o setor imobiliário sabe da associação paradoxal que seus consumidores têm com os conceitos de segurança e liberdade, além de tentarem se distanciar da cidade como espaço caótico, violento, desordenado e mal cuidado. Anúncios imobiliários representam os condomínios como "ilhas instaladas no meio de arredores nobres" (CALDERA, 2000, p. 266).

Não há menção a aparatos de segurança como o principal atributo dos empreendimentos, ainda que seja uma correlação lógica que a palavra "residencial" signifique, no caso, espaço fechado, com portaria e controle de acesso. Como Caldera (2000) observou nos anúncios da RMSP, não há menção explícita de desejo por vida em comunidade nas peças de marketing, o que revela o que se espera de pessoas que desejam conviver isoladas entre iguais.

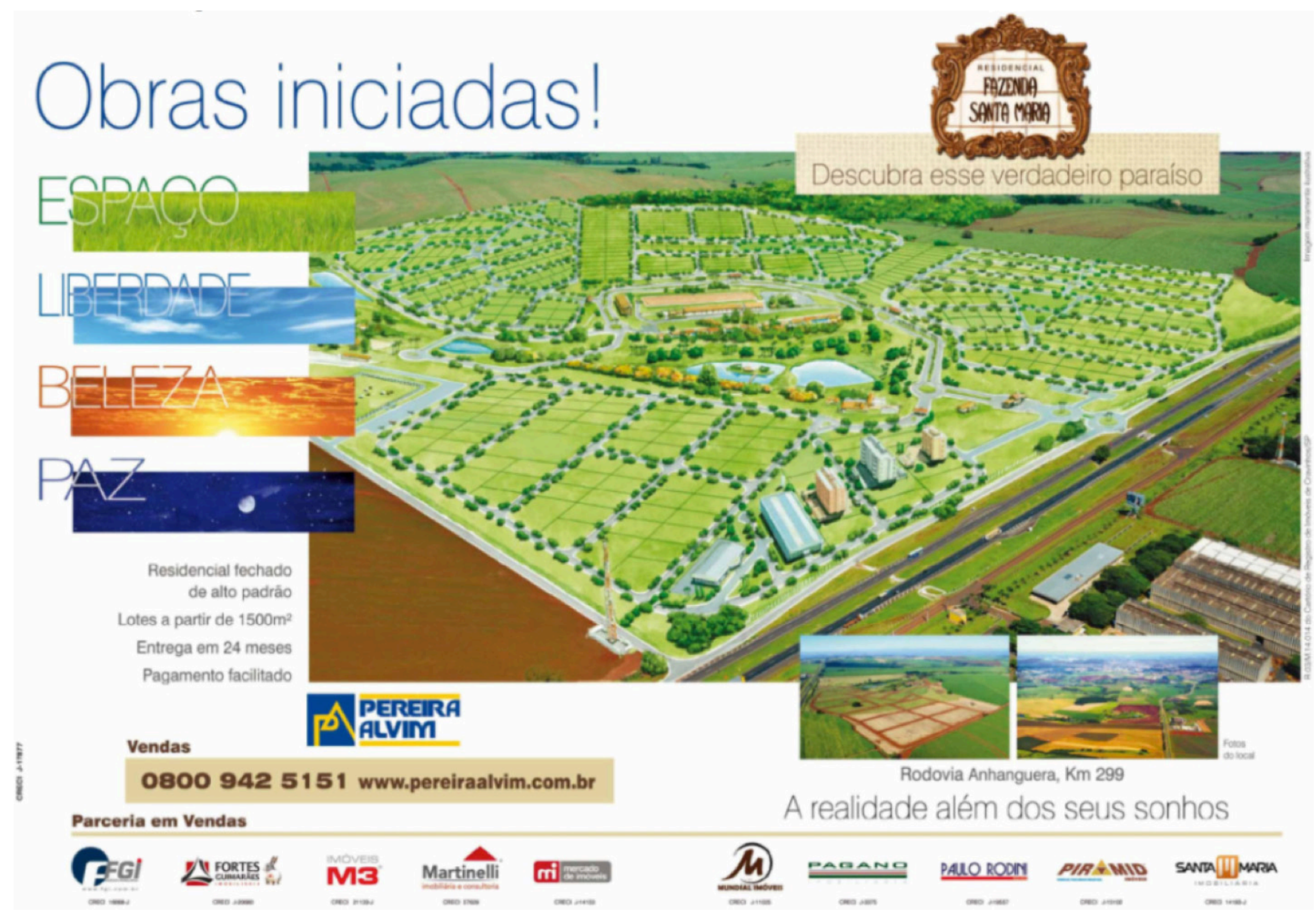

risco. 17_2 

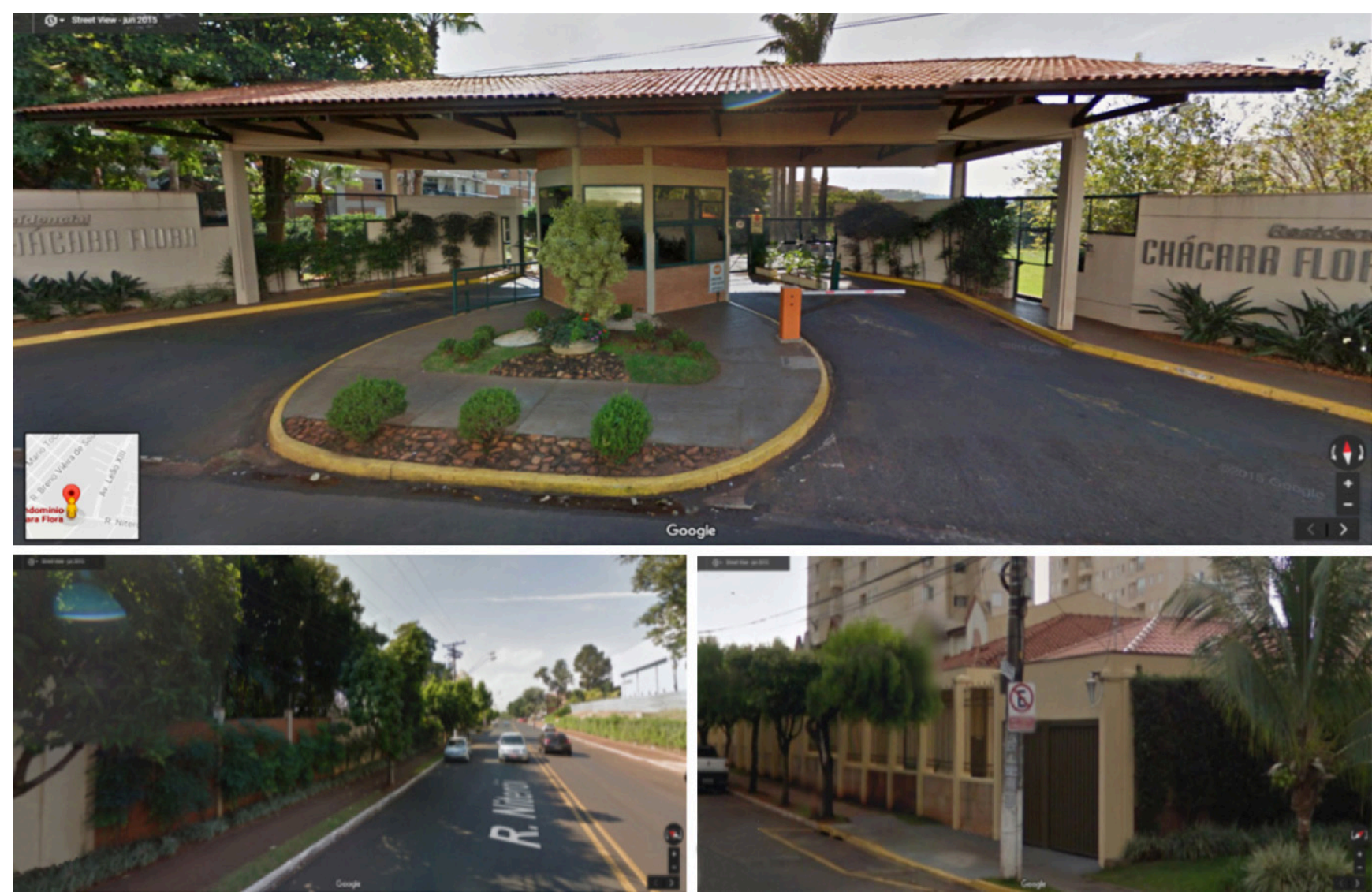

Figura 5: Portaria do Condomínio Residencial Chácara Flora (topo) e muros com cerca elétrica deste condomínio (esquerda) e do Village de France (direita). Fonte: elaborado pelo autor, com o auxílio da ferramenta Street View da Google.

\section{Arquitetura defensiva e sociabilidade interna}

Para assegurar segurança e status, é imprescindível consumar o caráter fortificado dos enclaves. E, para que a segregação não seja apenas física, mas também simbólica, os enclaves se valem não apenas de uma medida defensiva, mas de um conjunto delas, moldando uma nítida estratégia de evitação sustentada por barreiras.

Dos quatro enclaves residenciais visitados para as entrevistas, há pouca variação nas estratégias de segurança: todos são guarnecidos por portarias com vidros de insufilm escuro ou espelhado, evitando a visão interna de funcionários e dos sistemas de seguranças; possuem cancelas separadas para a entrada de moradores e visitantes; interfones nas casas ou apartamentos conectados com a portaria; sistema de câmeras de segurança instalados em pontos chave; muros equipados com cerca elétrica e, no caso do setor sul, com concertinas clipadas, típicas de presídios; serviço integral ou apenas noturno de ronda e eventual identificação de nome e identificação dos visitantes (Figuras 5 e 6).

A combinação desses fatores resulta em uma estética de segurança ostensiva. No setor sul se tornou comum a situação na qual uma via pública é margeada por muros equipados com concertinas duplas e cercas elétricas: são quilômetros de vias públicas nessa situação, não apenas áreas ocasionais. Aos muros, somam-se calçadas estreitas e paisagismo que não contribui para o conforto térmico dos pedestres, suscitando um cenário de abandono, de cidade desabitada. 
Figura 6: Portaria do loteamento residencial Vista Bella: muros com cerca elétrica e câmeras de segurança interna. Fonte: elaborado pelo autor, com o auxílio da ferramenta Street View da Google.
Não se vê pessoas utilizando essas vias, pois foram projetadas para serem desconfortáveis e não atrativas para pedestres, cujo uso é praticamente exclusivo dos automóveis. É flagrante também a ausência de pontos de ônibus no espaço público que os circunda, dificultando o acesso dos trabalhadores pobres empregados nesses enclaves.

No que se refere à sociabilidade interna, ainda que todos relatem conhecer ao menos os seus vizinhos antigos e realizar atividades esporádicas em conjunto, reconhecem que, com o passar do tempo, há dificuldade de se conhecer novos moradores. É central também o papel das crianças na sociabilidade interna de seus moradores, pois elas motivam seus pais a frequentarem as áreas de lazer comuns do condomínio e assim a conviver e se relacionar com os pais das outras crianças.

A fortificação também constitui um traço marcante das instituições de ensino. A Fundação Armando Álvares Penteado (FAAP), por exemplo, é uma das escolas mais caras e cobiçadas da cidade - o que torna bastante seletivo o acesso a esta instituição
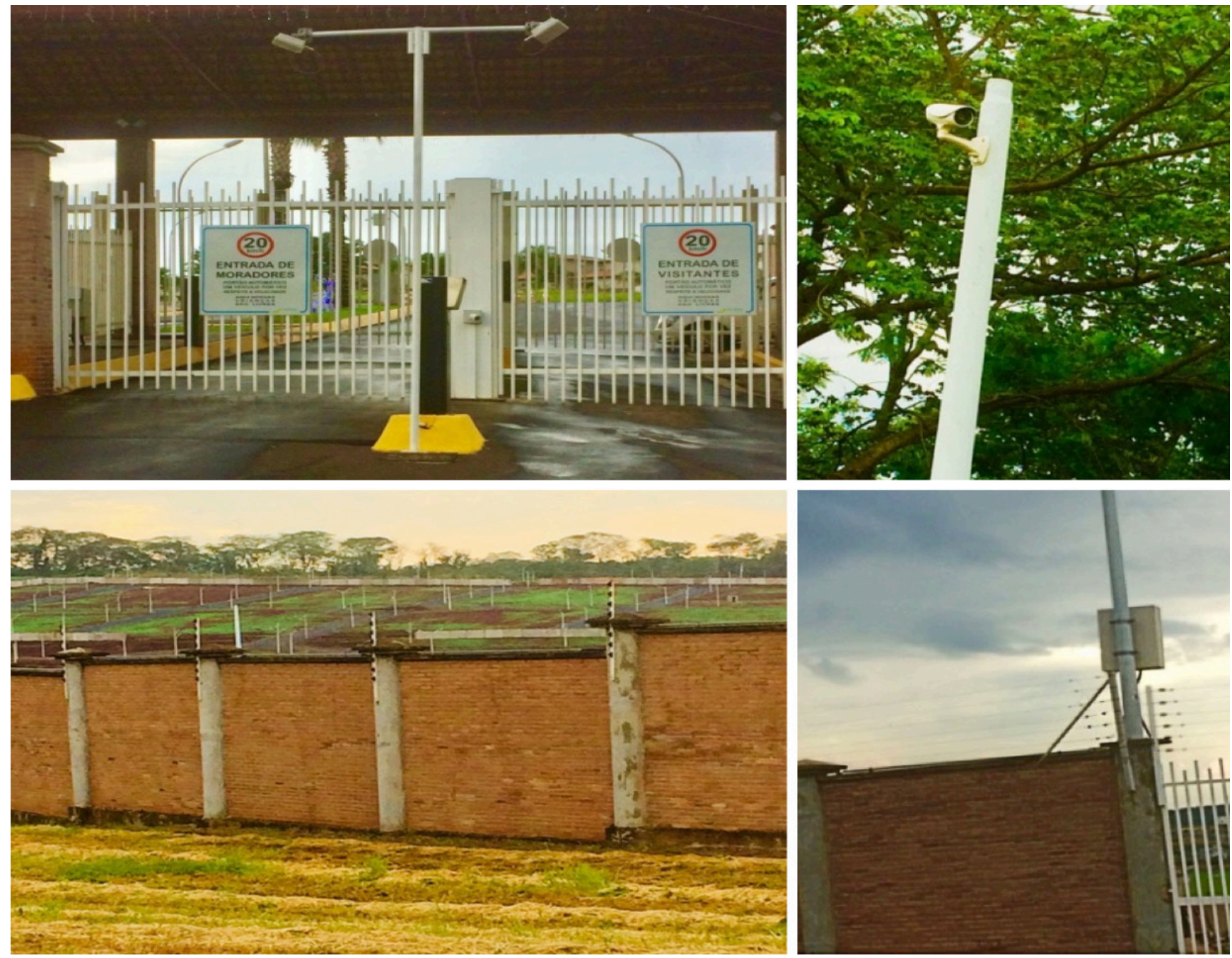
Figura 7 (topo): Fundação Armando Álvares Penteado - Portarias de acesso. Fonte: Site da instituição <faap.br/colegiorp/ infraestrutura.asp > e ferramenta Street View da Google. Acesso: 30 nov. 2017.

Figura 8 (embaixo): Ribeirão Preto - Imagem da parte norte do subsetor Sul 9 (S9). Fonte: elaborado pelo autor, com o auxílio da ferramenta Street View da Google. privada - e em seus dois prédios contíguos há portarias e catracas, além de ser comum ver seguranças fazendo ronda pelo quarteirão (Figura 7). Também neste caso, os princípios a serem seguidos são o da segurança e da homogeneidade social, além de mecanismos que evitem o ingresso dos "dessemelhantes".

Fato é que "as estruturas urbanas e o planejamento influenciam o comportamento e as formas de funcionamento das cidades" (GEHL, 2014, p. 9). A arquitetura defensiva nega o espaço público, gera fachadas horizontais passivas, sem a presença de atividades e pessoas, o que, de acordo com Gehl (2014), prejudica a experiência sensorial do pedestre. Efeito esse desejado pelos enclaves fortificados residenciais, os quais tendem a suprimir a vida urbana nos seus arredores.

A presença desses empreendimentos gera situações de profunda desorientação, criando um sistema de ruas interligadas por rotatórias genéricas que eventualmente chegam a alguma rodovia (Figura 8). Esse problema, somado ao cenário das vias públicas
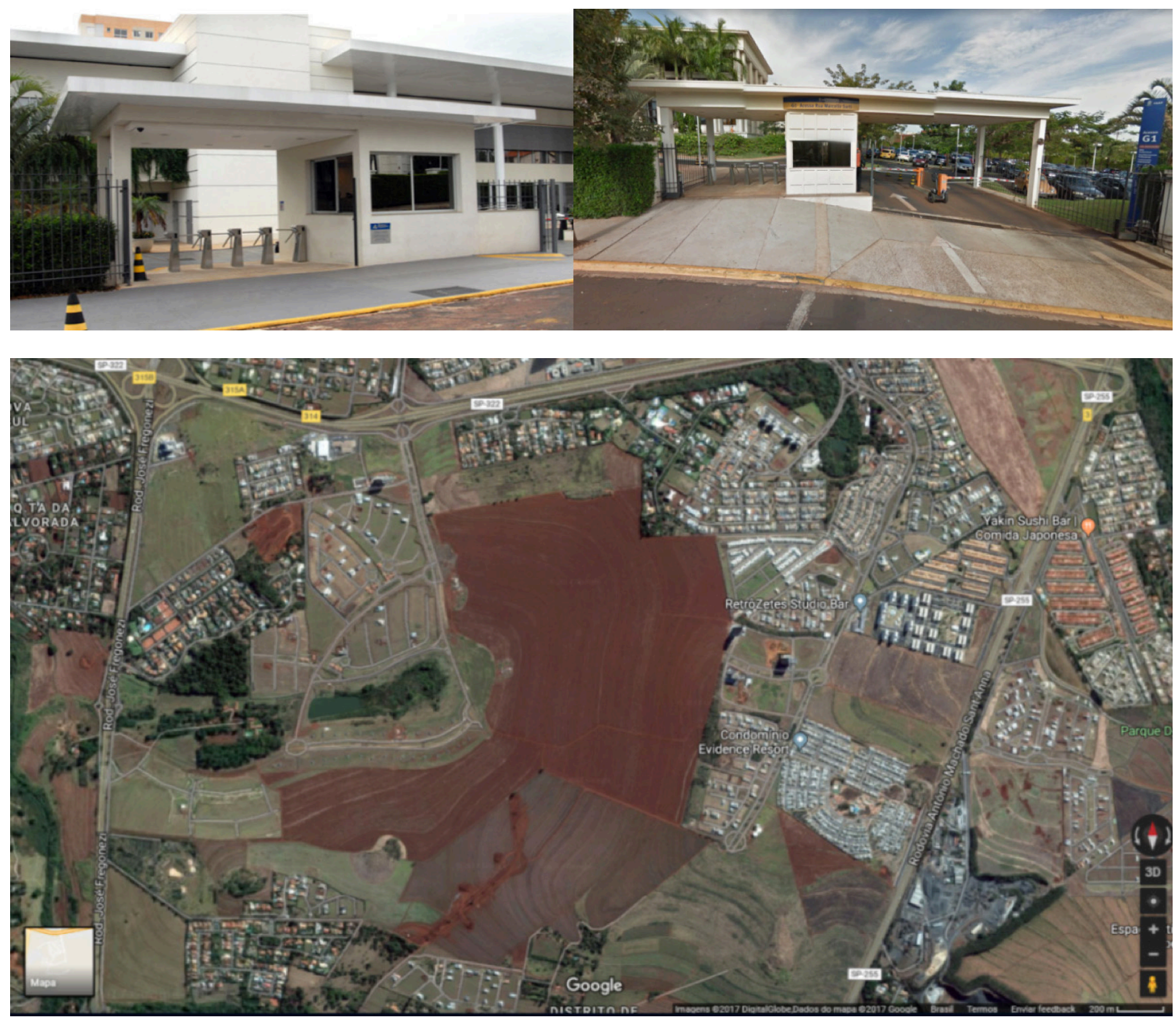

risco. 17_2 
margeadas por muros, deixou o setor sul sem pontos de referência, monofuncional e sem vida, já que os dois grandes complexos formados pelo Ribeirão Shopping e pelo Shopping Iguatemi centralizam serviços de comércio, lazer e consumo.

As franjas das periferias dos setores sul e leste apresentam descontinuidades urbanas, com a presença intercalada de enclaves residenciais e vazios urbanos. A malha urbana é fragmentada e sem conexões viárias satisfatórias. Pensar na relação destes enclaves com o espaço aberto da cidade evidencia um relacionamento conflituoso para seus moradores não apenas no âmbito das regras, mas também na relação com não residentes de enclaves. Perguntas sobre sociabilidade geraram as respostas com maiores divergências entre os entrevistados. Muitos pediram para que a pergunta fosse repetida e reformulada, além de mostrarem clara surpresa por serem questionados sobre os impactos sociais que seu modo de morar poderia gerar e na percepção que "os outros" podem ter deles: tentar se colocar na posição de quem também é julgado gerou desorientação.

\section{Considerações Finais}

Os enclaves fortificados em Ribeirão Preto se concentram no setor sul, processo que se intensificou a partir dos anos de 1990. A ação de grandes empreendedores tem se concretizado com a expansão e construção de shoppings centers, complexos de torres de negócio e de apartamentos, condomínios e loteamentos fechados, e escolas privadas. A regulação urbana correspondente tem sido permissiva, o que produz incentivos à sua continuidade.

Os conflitos relativos às Leis de Parcelamento, Uso e Ocupação do Solo e do Plano Diretor tornam explícita a influência do setor da construção civil nas decisões da legislação urbanística. Ao mesmo tempo em que o Plano Diretor de 2014 foi rejeitado por tratar de um artigo que comprometeria a proteção ambiental do Aquífero Guarani, um novo texto para a lei, de 2017, pode ser aprovado com a autorização de urbanização das áreas desta reserva, em nítido movimento de liberação de áreas de grande valor para o mercado imobiliário devido à sua localização nobre no setor leste. A tentativa de regularizar a figura jurídica do loteamento fechado foi malsucedida, já que declarada inconstitucional, mas nenhuma penalidade é aplicada àqueles se que se mantêm em situação irregular.

Para Bauman (2009), a cidade foi historicamente o lugar do convívio com o diferente, mas passa a temê-lo na sociedade pós-moderna, de sorte que a segregação espacial é um paliativo fadado ao fracasso ou ao aumento da paranoia e da vigilância, as quais

10 Compreensão semelhante foi antecipada por Jane Jacobs em sua obra clássica, "Morte e vida de grandes cidades".

11 Invertida em comparação ao modelo proposto por T.A. Marshall para interpretar a trajetória inglesa, na qual a ordem de conquista coloca os direitos civis na base da construção da cidadania, seguidos, respectivamente, pelos direitos políticos e, finalmente, pela difusão de direitos sociais. deseducam esses grupos autosegregados a conviverem com o diferente de forma pacífica, aumentando a sensação de violência. Para Ghel (2014) a vida na cidade requer o encontro entre os diferentes, pois a socialização e o convívio com outras pessoas, além de um desejo inerente à natureza humana, são requisitos para tornar as cidades mais seguras. ${ }^{10}$

No que se refere à cidadania, para Carvalho (2001) este é um fenômeno que se deu de maneira inversa no Brasil ${ }^{11}$, de forma que os direitos civis - direito à liberdade individual, à igualdade, à propriedade, à livre circulação - "apresentam as maiores deficiências em termos de seu conhecimento, extensão e garantias" (CARVALHO, 2001, p. 228). 
Ainda que outras modalidades de enclaves fortificados tenham estatuto jurídico legal - shoppings, condomínios, instituições privadas de ensino -, há evidente esforço para garantir sua homogeneidade social. Essa constatação contrasta com as falas dos entrevistados, nas quais frequentemente apareceu a ideia de que o direito deles (de ir e vir) era comprometido pela criminalidade. No caso, criminalidade e violência associada automaticamente aos pobres.

No Brasil contemporâneo há, com efeito, uma "democracia disjuntiva", na qual vigoram "processos contraditórios que marcam a sociedade", e o universo do crime a explicita na medida em que a violência, além de deteriorar os direitos dos cidadãos, "oferece um campo no qual as reações à violência tornaram-se não apenas violentas e desrespeitadoras de direitos, mas ajudam a deteriorar o espaço público, a segregar grupos sociais e a desestabilizar o estado de direito" (CALDEIRA, 2000, p. 56).

As evidências da pesquisa empírica validam o conceito de enclaves fortificados (CALDERA, 2000), também apropriado para a interpretação do caso de Ribeirão Preto tendo em vista que esses espaços possuem os mesmos atributos físicos e arquitetônicos e geram as mesmas consequências sociais e urbanísticas observadas pela autora na RMSP. No entanto, os impactos socioespaciais gerados pelos enclaves fortificados em São Paulo diferem, na sua gradação e escala, dos observados em Ribeirão Preto.

Os enclaves fortificados em Ribeirão Preto não geraram espaços homogêneos apenas dentro dos muros, mas homogeneidade em todo um setor, o sul, além de influenciar as áreas a sudeste e a sudoeste. A atratividade dos enclaves fortificados não reproduziu a formação de cenários como de São Paulo, onde espaços extremamente pobres são divisados de espaços luxuosos apenas por muros e cercas. Em Ribeirão Preto, a morfologia urbana, a disponibilidade de glebas, a agressividade do mercado imobiliário e a própria legislação permitiram a formação de uma larga extensão territorial em que predominam enclaves e na qual praticamente não há circulação de cidadãos de grupos sociais diferentes.

Em Ribeirão Preto não se observa contrastes tão drásticos de desigualdade social convivendo lado a lado. Nota-se, no entanto, expressiva desigualdade setorial no território, em especial entre os setores norte e sul. Enquanto o norte foi ocupado pela população mais pobre por meio de conjuntos habitacionais implantados pela COHAB$\mathrm{RP}$, dando margem a um processo concomitante de favelização da área, o setor sul foi planejado pelo setor privado (e admitido pelo poder público) para ser ocupado pelos grupos socioeconômicos dominantes, de forma que há clara discrepância entre a qualidade e a quantidade de serviços e equipamentos públicos. Mais ainda: revela-se ausente o princípio da função social da propriedade e da cidade, preceito consagrado na Constituição cidadã e ratificado no Estatuto da Cidade.

Quanto maior a mixofobia - o medo de misturar-se (BAUMAN, 2009) -, maiores são as chances de estigmatização de grupos sociais, o que compromete o convívio entre citadinos na medida em que aumenta a intolerância. O fato de a mídia adotar uma narrativa única, a da violência e criminalidade associadas aos pobres, alimenta medos e preconceitos das classes média-alta e alta, que passam a identificar o perigo no "dessemelhante", tornando essa parte da população em interlocutor a ser evitado. 
Conviver em espaços socialmente homogêneos não contribui para a resolução dos problemas de violência e criminalidade, pelo contrário, estimula o aumento de segregação e da intolerância, além de comprometer o avanço da cidadania, notadamente dos direitos sociais e civis, já que usuários de enclaves tendem a se preocupar não com a sua relação com a cidade e seus habitantes como um todo, mas apenas com suas próprias formas insuladas de vivência.

\section{Referências bibliográficas}

BAUMAN, Zygmunt. Confiança e medo na cidade. 1. ed. Rio de Janeiro: Zahar, 2009.

ESTATUTO DA CIDADE: Guia para implementação pelos municípios e cidadãos: Lei n 10.257, de 10/7/2001, que estabelece diretrizes gerais da política urbana. 2. ed. Brasília: Câmara dos Deputados, Coordenação de Publicações, 2002.

CALDEIRA, Teresa Pires do Rio. Cidade de muros: crime, segregação e cidadania em São Paulo, tradução de Frank de Oliveira e Henrique Monteiro. São Paulo: Editora 34/Edusp, 2000

Enclaves Fortificados: a nova segregação urbana. Novos Estudos Cebrap, n. 47, 1997.

CARVALHO, José Murilo de. Cidadania no Brasil: o longo caminho. Rio de Janeiro: Civilização Brasileira, 2001.

DAL POZZO, Clayton Ferreira. Fragmentação socioespacial em cidades médias paulistas: os territórios do consumo segmentado de Ribeirão Preto e Presidente Prudente. Tese (Doutorado) em Geografia - Programa de Pós-Graduação em Geografia da Universidade Estadual Paulista (UNESP), Presidente Prudente, 2015.

FERNANDES, Maria Esther. et al. A cidade e seus limites: as contradições do urbano na "Califórnia Brasileira". São Paulo: Annablume; Fapesp; Ribeirão Preto: Unaerp, 2004.

FIGUEIRA, Tânia Maria Bulhões. Produção social da cidade contemporânea: análise dos condomínios urbanísticos e loteamentos fechados de alto padrão do subsetor sul de Ribeirão Preto - SP. Dissertação (Mestrado) em Arquitetura e Urbanismo - Instituto de Arquitetura e Urbanismo da Universidade de São Paulo, São Carlos, 2013.

GEHL, Jan. Cidades para pessoas. 2. ed. São Paulo: Perspectiva S.A., 2014.

GOULART, Jefferson Oliveira; BENTO, Patricia Pechini. Enclaves fortificados e segregação urbana: o caso de Jundiaí. Sociedade e Cultura, v. 14, n. 1, jan./jun. 2011.

IBGE. Censo Demográfico 2010. Disponível em <https://cidades.ibge.gov.br/brasil/sp/ribeirao-preto/panorama>. Acesso: 31 out. 2017.

KOWARICK, Lúcio. Espoliação Urbana. Rio de Janeiro: Paz e Terra, 1979.

NEGRI, Barjas. As políticas de descentralização industrial e o processo de interiorização em São Paulo: 1970-1985. In: TARTAGLIA, J.C. \& OLIVEIRA, O.L. (orgs.). Modernização e desenvolvimento do interior de São Paulo. São Paulo: Ed. UNESP, 1988.

PECCI, Guilherme Moreira. Interior de muros: expansão e formação de condomínios e loteamentos fechados em Ribeirão Preto. Monografia de Pós-Graduação. Ribeirão Preto: FAAP, 2014.

SANTOS, Milton. A urbanização brasileira. São Paulo: Hucitec, 1993.

SENNETT, Richard. O declínio do homem público: as tiranias da intimidade. São Paulo, Companhia das Letras, 1993.

SPOSITO, Maria Encarnação Beltrão; GOÉS, Eda Maria. Espaços fechados e cidades: insegurança urbana e fragmentação socioespacial. São Paulo: Ed. Unesp, 2013.

SOUZA, Jessé. A radiografia do golpe: entenda como e porque você foi enganado. Rio de Janeiro: LeYa, 2016. 